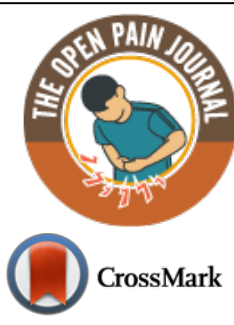

RESEARCH ARTICLE

\title{
Multimodal Analgesia Transversus Abdominis Plane Block-Ketorolac Combination being Superior to Paracetamol-Ketorolac as Postoperative Pain Management after Cesarean Section in an Indonesian Hospital
}

\author{
Isngadi $^{1, *}$, Djudjuk R. Basuki ${ }^{1}$, Eko Nofiyanto ${ }^{1}$ and Ristiawan M. Laksono ${ }^{1}$ \\ ${ }^{I}$ Department of Anesthesiology and Intensive Therapy, Faculty of Medicine, Brawijaya University, Indonesia
}

\begin{abstract}
:
Aim:

This study aimed to compare the outcome of multimodal analgesia using transversus abdominis plane block combined with ketorolac and multimodal analgesia oral paracetamol combined with ketorolac in postoperative pain after cesarean section.

Background:

Post-caesarean section pain resulted in prolonged recovery time, inhibited early breastfeeding initiation, and prolonged hospitalization. Multimodal analgesia is an important component of post-cesarean section pain management but has not been established in many Indonesian hospitals.

Methods:

This study was a retrospective, observational analytic study on 46 patients who received low-dose sub-arachnoid block anesthesia. A total of 24 subjects received bilateral transversus abdominis plane block employing ultrasonography-guided lateral approach, with Ropivacaine $0.25 \%$ in a total volume of $30 \mathrm{cc}$ combined with intravenous ketorolac $30 \mathrm{mg} / 8 \mathrm{~h}$ (Group B). A total of 22 subjects received oral paracetamol $500 \mathrm{mg} / 6 \mathrm{~h}$ combined with intravenous ketorolac $30 \mathrm{mg} / 8 \mathrm{~h}$ (Group A). Numeric Rating Scale (NRS), length of hospitalization, and mobilization time were analyzed using the T-test at a significance level of $\mathrm{p}<0.05$ (confidence interval of $95 \%$ ).

Results:

The NRS and mean time to start mobilization of patients who received transversus abdominis plane block combined with ketorolac were significantly better than patients who received paracetamol combined with ketorolac $(p<0.05)$. There was no significant difference in the length of hospitalization between the two techniques $(\mathrm{p}>0.05)$. Both modalities resulted in improvement in pain intensity over the mild pain range.

Conclusion:

Multimodal analgesia transversus abdominis plane block combined with ketorolac is superior to paracetamol combined with ketorolac for postoperative pain management after cesarean section.
\end{abstract}

Keywords: Postoperative pain, Multimodal analgesia, Transversus abdominis plane block, Paracetamol, Ketorolac, Cesarean section.

\begin{tabular}{|l|l|l|l|} 
Article History & Received: June 23, 2021 & Revised: October 11, 2021 & Accepted: November 10, 2021
\end{tabular}

\section{INTRODUCTION}

In the few decades, cesarean section deliveries have become more common to terminate the pregnancy. Globally, it is estimated that $15 \%$ of deliveries are performed by cesarean section. In Europe, $21.1 \%$ of deliveries are performed by cesarean section and $32 \%$ in the United States [1,2]. In Indonesia, the cesarean section has increased significantly from the year $2010-2013$, growing from $9.8 \%$ to $17.6 \%$ [3].

\footnotetext{
* Address correspondence to this author at the Department of Anesthesiology and Intensive Therapy, Faculty of Medicine, Brawijaya University/Dr. Saiful Anwar General Hospital, Malang, Indonesia; E-mail: drisngadi@ub.ac.id
}

Patients potentially experience postoperative pain after undergoing cesarean section. Postoperative pain is caused by surgical trauma and inflammation that promote somatic and visceral pain. Somatic pain in cesarean section arises from noxious stimuli on nociceptors due to skin incisions, whereas visceral pain arises from the incision and uterine contractions. Apart from hormonal changes in pregnancy, psychosocial and emotional factors also play a role in postoperative pain. The mean pain score in the cesarean section was found as 4.7 (moderate pain), higher than spontaneous delivery (3.3 or mild pain) $[1,4]$. It is essential to understand the risk factor of chronic postoperative pain development. The postoperative 
pain causes disruption in the postpartum period, prolonged recovery time, inhibition of early breastfeeding initiation in infants, more extended hospital stays, and even morbidity of the mother $[2,5,6]$. Postoperative pain that is inadequately handled increases the risk of chronic pain up to 2.5 times. The data show that six months after cesarean section, $12.3 \%$ of patients experienced persistent pain in the operation area, while $6 \%$ of parturients experienced chronic pain one year after the cesarean section $[1,7,8]$.

The American Society of Regional Anesthesia recommends some postoperative pain management modalities, including pharmacological therapy (opioid, non-opioid with Non-Steroidal Anti-inflammatory Drugs (NSAIDs) and paracetamol), local anesthesia in the area of the incision, regional anesthesia technique (transversus abdominis plane block), neuraxial anesthetic techniques (epidural, intrathecal opioids), and non-pharmacological therapy (cognitive modalities, transcutaneous electrical nerve stimulation) [9]. Opioids (fentanyl, morphine, meperidine) are the most widely used pharmacological therapies after cesarean section, either intravenous or neuraxial. However, opioid use has many side effects, such as decreased lactation, sedation, respiratory depression, pruritus, nausea, vomiting, constipation, and urinary retention. NSAIDs (ketorolac) play a significant role in visceral pain, but postoperative pain scores persist at 4.14 [10]. Multimodal analgesia may prove to be promising in postoperative pain management as it can exert minimal side effects using opioids and enable a faster recovery period [5]. Multimodal analgesia combines different techniques and medications in order to induce minimum side effects $[11,12]$.

In Dr. Saiful Anwar General Hospital, Indonesia, cesarean section is mostly done with regional anesthesia subarachnoid block. Post-cesarean section pain management mostly uses multimodal analgesia intravenous ketorolac combined with oral paracetamol. However, there exist no empirical data yet regarding those combinations' outcomes in Dr. Saiful Anwar General Hospital in Indonesia. Our study aims to compare the outcomes of multimodal analgesia ketorolac-paracetamol and transversus abdominis plane block-ketorolac for postoperative pain management after cesarean section.

\section{METHODS}

The study was a retrospective analytic observational study conducted in Dr. Saiful Anwar General Hospital, Indonesia, between January 2020-August 2020. The study was approved by the Dr. Saiful Anwar Health Research Ethics Committee (No. 400/221/K.3/302/2020). The study population included parturients who underwent cesarean section. The study subjects were distributed into two groups. Group A received multimodal analgesia intravenous (IV) ketorolac combined with oral paracetamol, while group B received multimodal analgesia transversus abdominis plane block combined with ketorolac. The number of study subjects was calculated based on the following formula proposed by Dahlan [13].

$$
\begin{gathered}
n 1=n 2=2\left(\frac{(Z \alpha+Z \beta) S}{X 1-X 2}\right) \\
S g=\frac{\left[S 1^{2} \times(n 1-1)+S 2^{2} \times(n 2-1)\right]}{n 1+n 2-2}
\end{gathered}
$$

$\mathrm{n}=$ the number of the minimum sample

$\mathrm{Z} \alpha=$ deviation $\alpha=0.05$ (1.64)

$Z \beta=$ deviation $\beta=0.10(1.28)$

$\mathrm{X}_{1}-\mathrm{X}_{2}=$ the difference in the minimum mean which is considered significant (1.5)

$\mathrm{Sg}=$ standard deviation $\mathrm{n} 1$ and $\mathrm{n} 2$

$\mathrm{S} 1=$ standard deviation of the previous study for $\mathrm{n} 1$

$\mathrm{S} 2=$ standard deviation of the previous study for $\mathrm{n} 2$

Based on the formula, in each group, the minimum number of subjects was $(n)=19.4$. Due to $n 1=n 2$, the total number of study subjects was 20 in each group (or 47 in total). The inclusion criteria involved parturients who underwent cesarean section using spinal anesthesia; half of the parturients received transversus abdominis block multimodal analgesia, while the other half received paracetamol orally, ASA status 1, 2, 3. The exclusion criteria included parturients who received general anesthesia, and whose medical data were incomplete.

The subjects were chosen using the randomization technique by the medical data record administrator who did not participate in the study. After randomization, 46 subjects who met the inclusion criteria were selected.

Group A $(n=22)$ received a multimodal analgesia regimen of oral paracetamol $500 \mathrm{mg}$ every 6 hours combined with ketorolac $30 \mathrm{mg}$ (i.v) every 8 hours. Group B $(n=24)$ received multimodal analgesia bilateral transversus abdominis plane block using Ultrasound guidance with Ropivacaine $0.25 \%$ in a total volume of $30 \mathrm{cc}$ combined with ketorolac $30 \mathrm{mg}$ (i.v.) every 8 hours. Transversus abdominis plane block is an afferent nerve block technique performed by injecting a local anesthetic regimen into the fascia plane between the transverse abdominis and oblique internal muscles. The study assesses the Numeric Rating Scale (NRS) 22 and 24 hours postoperatively, time of starting mobilization, and the length of hospitalization.

\subsection{Statistical Analysis}

We used the confidence interval (CI) of $95 \%$ and $\alpha=0.05$. The data were analyzed using a T-test and employing Statistical Package for Social Sciences (SPSS) (version 18.0, IBM Statistic, United Stated) to analyze the difference in NRS between the two groups (significant if $\mathrm{p}$-value $<0.05$ ). Before performing the T-test, all the data were tested for normality and homogeneity. The data not normally distributed (significant at p-value $>0.05$ ) were analyzed using the non-parametric MannWhitney test (significant at $\mathrm{p}$-value $<0.05$ ).

\section{RESULTS}

46 patients who underwent cesarean section under spinal anesthesia with different postoperative pain management were selected for the study. The characteristics of the subjects are shown in Table 1. Subjects in both the groups were homogeneous ( $p>0.05)$ (Table 1). Post-operative pain intensity after multimodal analgesia was evaluated based on the subject's NRS (at rest and movement), the subject's ability to start mobilization, and duration of hospitalization. There were significantly different NRS results during rest and movement 
between group A and group B (p-value <0.05) $12 \mathrm{~h}$ and $24 \mathrm{~h}$ postoperative (Fig. 1). The NRS at rest and movement of group B was significantly lower than group A.

Table 1. Demographic characteristics of the study subjects.

\begin{tabular}{|c|c|c|c|}
\hline Characteristic & Group B (n=24) & Group A (n=22) & p-value \\
\hline Age (mean) & 30.71 & 29.14 & 0.391 \\
\hline Physical status & & & \\
• ASA 1 & - & - & \\
- ASA 2 (n) & 16 & 12 & 0.405 \\
- ASA 3 (n) & 8 & 10 & \\
\hline
\end{tabular}

Group B: subjects received bilateral transversus abdominis plane block employing ultrasonography-guided lateral approach (Ropivacaine regimen $0.25 \%$ in a total volume of $30 \mathrm{cc}+$ ketorolac (IV) $30 \mathrm{mg}$ every 8 hours); Group A: subjects received oral paracetamol $500 \mathrm{mg}$ every 6 hours + ketorolac (IV) $30 \mathrm{mg}$ every 8 hours; T-test significant at p-value $<0.05$.

Group B significantly needed a shorter time to start mobilization after the cesarean section than group $A(p<0.05)$. Group B needed $21.83 \mathrm{~h}$ postoperative to start mobilization, while group A required $30.36 \mathrm{~h}$ to start mobilization (Fig. 2). Subjects in group B exhibited a lower duration of postoperative hospitalization (3.79 days) than group A (4.36 days). However, the statistical test showed no significant difference $(\mathrm{p}>0.05)$ (Fig. 3).

\section{DISCUSSION}

Multimodal transversus analgesia abdominis plane block combined with ketorolac was found to be more effective than the combination of paracetamol and ketorolac. Based on the NRS score in the first $24 \mathrm{~h}$ postoperative, the transversus abdominis plane block combined with ketorolac reduced the NRS post-cesarean section. The mean NRS was 4.7 (moderate pain) in the first 24 hours [4]. In this study, the NRS for postoperative 24 hours was $0.71-1.5$. The pain intensity ranged from no pain to mild pain.

Multimodal analgesia combination comprising transversus abdominis plane block and ketorolac reduced the dosage of the anesthetic agent and increased the analgesic effect of the analgesic agent. Kasensin et al. state that the use of single ketorolac as analgesia can reduce visceral pain, but the mean NRS score postoperative is 4.14 [10]. This study shows that ketorolac's combination with other modalities increases the effect of ketorolac in reducing the degree of postoperative pain.

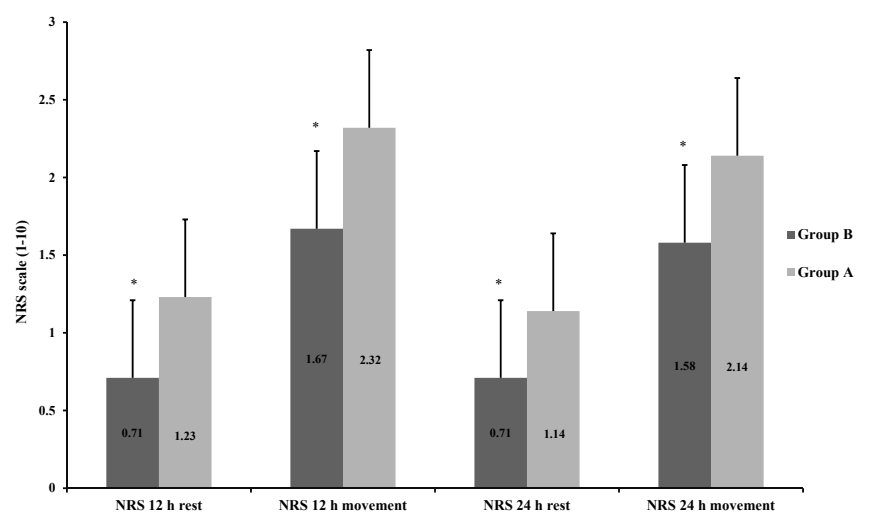

Fig. (1). NRS for Group B was significantly lower than group A, both at 12 hours post-surgery and 24 hours post-surgery. Group B: subjects received bilateral transversus abdominis plane block with ultrasonography-guided lateral approach (Ropivacaine regimen $0.25 \%$ in total volume of 30 cc + ketorolac (IV) $30 \mathrm{mg}$ every 8 hours); Group A: subjects received oral paracetamol $500 \mathrm{mg}$ every 6 hours + ketorolac (IV) 30 mg every 8 hours. * indicates that the group was significantly different.

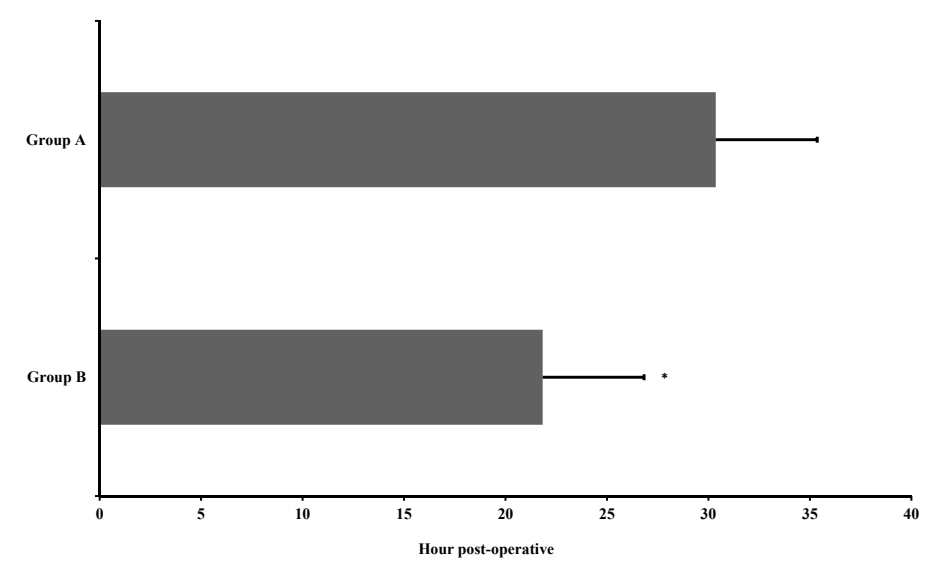

Fig. (2). Group B significantly required a shorter duration to start mobilization postoperatively compared to group A. Group B: subjects received bilateral transversus abdominis plane block employing ultrasonography-guided lateral approach (Ropivacaine regimen $0.25 \%$ in total volume of 30 cc + ketorolac (IV) 30 mg every 8 hours); Group A: subjects received oral paracetamol 500 mg every 6 hours + ketorolac (IV) 30 mg every 8 hours. * indicates that the group was significantly different. 


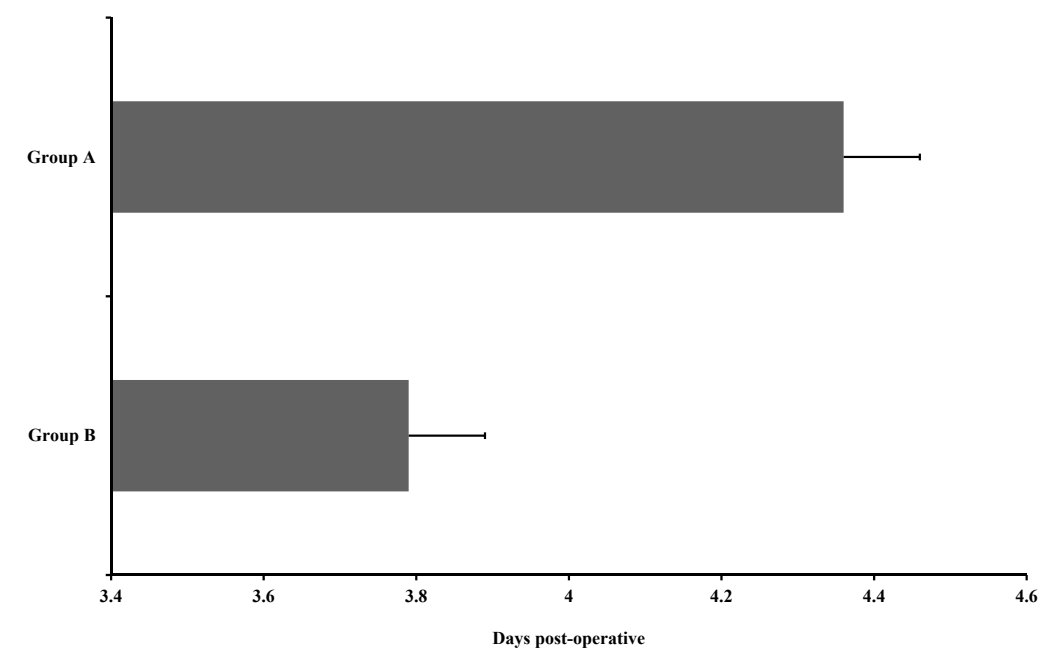

Fig. (3). Group B needed a shorter duration of hospital stay compared to group A. Group B: subjects received bilateral transversus abdominis plane block employing ultrasonography-guided lateral approach (Ropivacaine regimen $0.25 \%$ in total volume of $30 \mathrm{cc}+\mathrm{ketorolac}$ (IV) $30 \mathrm{mg}$ every 8 hours); Group A: subjects received oral paracetamol $500 \mathrm{mg}$ every 6 hours + ketorolac (IV) 30 mg every 8 hours. * indicates that the group was significantly different.

Paracetamol can act as an adequate analgesia at a dose of 600-1000 mg every 4-6 hours. At that dose, paracetamol decreased the initial pain intensity by $50 \%$ [14]. With the multimodal analgesia technique, the dose can be reduced and the analgesic effect can be increased [15]. This is consistent with our study where paracetamol $500 \mathrm{mg}$ every 6 hours combined with ketorolac reduced the pain intensity from moderate to mild pain post-cesarean section. The mean NRS at rest and movement in the patient who received ketorolac combined with paracetamol was lower than the mean NRS in the cesarean section, which was 4.7 in the first 24 hours. However, the NRS of the patients who received paracetamol combined with ketorolac was still higher than those who received transversus abdominis plane block combined with ketorolac.

The use of a low-dose anesthetic agent is one of the goals of multimodal analgesia. A study by $\mathrm{Ng}$ et al. using transversus abdominis plane block for the post-cesarean section with low dose Ropivacaine $(0.25 \%)$ showed reduced toxicity of local anesthetics. However, the analgesic effect and opioid-sparing effect did not differ with the intermediate $(0.375 \%)$ or high $(0.5 \%)$ dose [16]. The use of transversus abdominis plane block for post-cesarean analgesia provides lower pain intensity and reduces the use of opioid in post-cesarean section analgesics [17]. In this study, the combination of transversus abdominis plane block and ketorolac proved to be superior to paracetamol and ketorolac for post-cesarean section analgesia.

The postoperative pain disrupts the postpartum period, prolongs recovery time, inhibits early breastfeeding initiation in infants, and extends the hospital stay $[2,5]$. Patients with multimodal analgesia transversus abdominis plane block combined with ketorolac significantly had early mobilization than patients who received multimodal analgesia paracetamol combined with ketorolac. Early mobilization is associated with positive implications, such as faster recovery time, faster initiation of breastfeeding, and shorter hospital stay. Meanwhile, the longer time to start mobilization slow downs the recovery rate, interrupts the bonding between babies and mothers, and increases the length of hospital stay $[5,18]$.

Patients who received multimodal analgesia transversus abdominis plane block combined with ketorolac significantly had a shorter duration of hospital stay than patients who received multimodal analgesia paracetamol combined with ketorolac. This study supports the findings of previous studies stating that multimodal analgesia provides a shorter hospitalization duration, reduces adverse socioeconomic implications and increases the recovery times [19 - 21].

The limitation of the study is the minimum number of study subjects. This study is considered a pilot study and further studies need to be conducted involving a more significant number of study subjects.

\section{CONCLUSION}

Multimodal analgesia transversus abdominis plane block combined with ketorolac is superior to paracetamol combined with ketorolac as post-cesarean section analgesia.

\section{AUTHORS' CONTRIBUTION}

Isngadi, Djudjuk R. Basuki, Eko Nofiyanto, and Ristiawan M. Laksono contributed equally to conceptualization, literature search, data acquisition, data analysis, manuscript preparation, and manuscript review.

\section{ETHICS APPROVAL AND CONSENT TO PARTICIPATE}

This study has been approved by the Dr. Saiful Anwar Health Research Ethics Committee (No. 400/221/K.3/302/2020).

\section{HUMAN AND ANIMAL RIGHTS}

No animals were used in this research. All procedures performed in studies involving human participants were in accordance with the ethical standards of the institutional and/or research committee, and with the 1975 Declaration of Helsinki, as revised in 2013 . 


\section{CONSENT FOR PUBLICATION}

Informed consent was obtained from all the participants.

\section{AVAILABILITY OF DATA AND MATERIALS}

The data supporting the findings of the article are available within the article.

\section{STANDARDS OF REPORTING}

STROBE guidelines and methodologies were followed in this study.

\section{FUNDING}

None.

\section{CONFLICT OF INTEREST}

The authors declare no conflict of interest, financial or otherwise.

\section{ACKNOWLEDGEMENTS}

Declared none.

\section{REFERENCES}

[1] Verstraete S, Van de Velde M. Post-cesarean section analgesia. Acta Anaesthesiol Belg 2012; 63(4): 147-67. [PMID: 23610853]

[2] Sutton CD, Carvalho B. Optimal pain management after cesarean delivery. Anesthesiol Clin 2017; 35(1): 107-24 [http://dx.doi.org/10.1016/j.anclin.2016.09.010] [PMID: 28131114]

[3] Indonesian Ministry of Health Balitbangkes. Riskesdas National Report 2018Publishing Agency for Health Research and Development. Jakarta 2019; pp. 1-674.

[4] Chestnut DH. Chestnut's obstetric anesthesia. $5^{\text {th }}$ ed. Philadelphia: Elsevier 2014.

[5] Macones GA, Caughey AB, Wood SL, et al. Guidelines for postoperative care in cesarean delivery: Enhanced Recovery After Surgery (ERAS) Society recommendations (part 3). Am J Obstet Gynecol 2019; 221(3): 247.e1-9.

[http://dx.doi.org/10.1016/j.ajog.2019.04.012] [PMID: 30995461]

[6] Kintu A, Abdulla S, Lubikire A, et al. Postoperative pain after cesarean section: assessment and management in a tertiary hospital in a low-income country. BMC Health Serv Res 2019; 19(1): 68. [http://dx.doi.org/10.1186/s12913-019-3911-x] [PMID: 30683083]

[7] Lunde S, Petersen KK, Kugathasan P, Arendt-Nielsen L, SøgaardAndersen E. Chronic postoperative pain after robot-assisted laparoscopic hysterectomy for endometrial cancer. J Gynecol Surg 2019; 35(3): 140-6.

[http://dx.doi.org/10.1089/gyn.2018.0068]

[8] Eisenach JC, Pan PH, Smiley R, Lavand'homme P, Landau R, Houle TT. Severity of acute pain after childbirth, but not type of delivery, predicts persistent pain and postpartum depression. Pain 2008; 140(1): 87-94.

[http://dx.doi.org/10.1016/j.pain.2008.07.011] [PMID: 18818022]

[9] Chou R, Gordon DB, de Leon-Casasola OA, et al. Management of postoperative pain: A clinical practice guideline from the American pain society, the American society of regional anesthesia and pain medicine, and the American Society of anesthesiologists' committee on regional anesthesia, executive commi. J Pain 2016; 17(2): 131-57. [http://dx.doi.org/10.1016/j.jpain.2015.12.008] [PMID: 26827847]

[10] Kasemsin. Effect of intravenous ketorolac on postoperative pain after cesarean section: A randomized double-blinded controlled trial. 2016; 100(3): 168-74.2016; Available from: http://www.who.int/trialsearch /Trial2.aspx?TrialID=TCTR20160330005

[11] Hadley EE, Monsivais L, Pacheco L, et al. Multimodal pain management for cesarean delivery: A double-blinded, placebocontrolled, randomized clinical trial. Am J Perinatol 2019; 36(11): 1097-105.

[http://dx.doi.org/10.1055/s-0039-1681096] [PMID: 30822800]

[12] Wick EC, Grant MC, Wu CL. Postoperativemultimodal analgesia pain management with non-opioid analgesics and techniques a review. JAMA Surg 2017; 152(7): 691-7.

[http://dx.doi.org/10.1001/jamasurg.2017.0898] [PMID: 28564673]

[13] Dahlan M. Sample size and method of internal sampling medical and health research. $3^{\text {rd }}$ ed. Salemba Medika 2009.

[14] Toms L, McQuay HJ, Derry S, Moore RA. Single dose oral paracetamol (acetaminophen) for postoperative pain in adults. Cochrane Database Syst Rev 2008; (4): CD004602. [http://dx.doi.org/10.1002/14651858.CD004602.pub2] [PMID: 18843665]

[15] Rosero EB, Joshi GP. Preemptive, preventive, multimodal analgesia: what do they really mean? Plast Reconstr Surg 2014; 134(4)(Suppl. 2): 85S-93S.

[http://dx.doi.org/10.1097/PRS.0000000000000671]

[PMID: 25255012]

[16] Ng SC, Habib AS, Sodha S, Carvalho B, Sultan P. High-dose versus low-dose local anaesthetic for transversus abdominis plane block postCaesarean delivery analgesia: a meta-analysis. Br J Anaesth 2018; 120(2): 252-63.

[http://dx.doi.org/10.1016/j.bja.2017.11.084] [PMID: 29406174]

[17] Sharkey A, Finnerty O, McDonnell JG. Role of transversus abdominis plane block after caesarean delivery. Curr Opin Anaesthesiol 2013; 26(3): 268-72.

[http://dx.doi.org/10.1097/ACO.0b013e328360fa16] [PMID: 23587731]

[18] Kehlet H. Postoperative pain, analgesia, and recovery-bedfellows that cannot be ignored. Pain 2018; 159(9)(Suppl. 1): S11-6. [http://dx.doi.org/10.1097/j.pain.0000000000001243] [PMID: 30113942]

[19] Beverly A, Kaye AD, Ljungqvist O, Urman RD. Essential elements of multimodal analgesia in enhanced recovery after surgery (ERAS) guidelines. Anesthesiol Clin 2017; 35(2): e115-43. [http://dx.doi.org/10.1016/j.anclin.2017.01.018] [PMID: 28526156]

[20] Patel SA, Gotkin J, Huang R, Darling C, Pates JA, Dolinsky B. Transversus abdominis plane block for postoperative analgesia after cesarean delivery. J Matern Neonatal Med 2012; 25(11): 2270-3. [http://dx.doi.org/10.3109/14767058.2012.685789] [PMID: 22591488]

[21] Patel SD, Sharawi N, Sultan P. Local anaesthetic techniques for postcaesarean delivery analgesia. Int J Obstet Anesth 2019; 40: 62-77. [http://dx.doi.org/10.1016/j.ijoa.2019.06.002] [PMID: 31262444]

\section{C) 2022 Isngadi et al.}

This is an open access article distributed under the terms of the Creative Commons Attribution 4.0 International Public License (CC-BY 4.0), a copy of which is available at: https://creativecommons.org/licenses/by/4.0/legalcode. This license permits unrestricted use, distribution, and reproduction in any medium, provided the original author and source are credited. 